APPLIED PHYSICAL CHEM!STRY 
A Macmillan Chemistry Text

Consulting Editor: Dr Peter Sykes, University of Cambridge 


\title{
APPLIED PHYSICAL CHEMISTRY
}

\section{HEALD}

Senior Lecturer in Physical Chemistry, Teesside Polytechnic

\author{
A. C. K. SMITH
}

Head of Department of Chemistry, Falkirk Technical College 


\author{
ISBN 978-1-349-01646-4 ISBN 978-1-349-01644-0 (eBook) \\ DOI 10.1007/978-1-349-01644-0 \\ () C. Heald and A. C. K. Smith 1974 \\ Reprint of the original edition 1974 \\ All rights reserved. No part of this publication may be \\ reproduced or transmitted, in any form or by any \\ means, without permission \\ First published 1974 by \\ THE MACMILLAN PRESS LTD \\ London and Basingstoke \\ Associated companies in New York Dublin \\ Melbourne Johannesburg and Madras
}

SBN 333140664 


\section{CONTENTS}

Preface xiii

Glossary of symbols $\quad$ xv

1 The Gaseous State 1

1.1 Pressure-Volume-Mass-Temperature Relationships for Ideal Gases 1 1.1.1 Dalton's law of partial pressures 1

1.1.2 Applications of the ideal gas equation 2

$\begin{array}{ll}1.2 \text { Diffusion of Gases } & 3\end{array}$

1.3 Kinetic Theory 4

1.3.1 Derivation of an expression for the pressure of a gas 4

1.3.2 Collision properties of gases 5

$\begin{array}{lll}\text { 1.3.3 The Boltzmann distribution law } & 7\end{array}$

1.4 Pressure-Volume-Mass-Temperature Relationships for Real Gases 9

$\begin{array}{lll}\text { 1.4.1 Intermolecular forces } & 9\end{array}$

$\begin{array}{ll}\text { 1.4.2 The van der Waals equation } & 11\end{array}$

$\begin{array}{lll}\text { 1.4.3 Other equations of state } & 13\end{array}$

$\begin{array}{ll}1.5 & \text { The Transition from Gas to Liquid } \\ 1.6 & 13\end{array}$

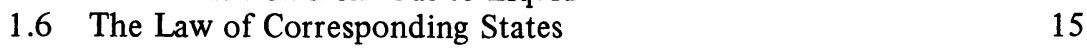

$\begin{array}{lr}\text { Further Reading } & 16\end{array}$

2 Thermochemistry 17

$\begin{array}{lll}2.1 & \text { Terminology } & 17\end{array}$

$\begin{array}{ll}2.1 .1 \quad \text { Properties of state } & 17\end{array}$

2.2 Heat and Work Produced by Chemical Reaction 18

$\begin{array}{ll}2.3 \text { Thermodynamic Energy } & 18\end{array}$

2.3.1 Heat absorbed or evolved at constant volume 19

2.3.2 Heat absorbed or evolved at constant pressure-enthalpy 19

$\begin{array}{ll}2.4 \text { Heat Capacity } & 20\end{array}$

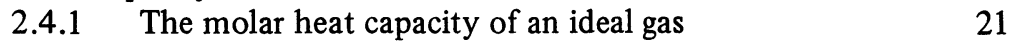

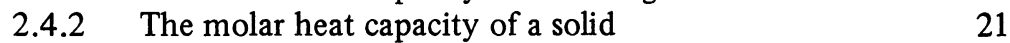

2.4.3 The variation of heat capacity with temperature 21

$\begin{array}{ll}2.5 & \text { Thermochemical Conventions } \\ 2.6 & 22\end{array}$

2.6 Enthalpy Changes of Specific Processes 23

2.7 The Relationship between $\Delta H$ and $\Delta U \quad 23$

2.8 Evaluation of $\Delta H$ and $\Delta U \quad 24$

2.8.1 Experimental determination 24

2.8.2 Indirect determination of $\Delta H$ and $\Delta U$-Hess's law 25

2.9 The Variation of $\Delta H$ and $\Delta U$ with Temperature 25

2.10 Applications of Thermochemical Measurements 27

$\begin{array}{ll}\text { Further Reading } & 33\end{array}$ 
3 The Thermodynamic Principles of Equilibrium 34

3.1 Increase in Disorder as a Driving Force 34

3.2 Thermodynamic Reversibility 34

3.2.1 The reversible isothermal expansion of an ideal gas 36

3.3 Entropy 36

3.3.1 Entropy of a phase change 37

3.3.2 Variation of entropy with temperature 38

3.3.3 The condition for equilibrium in an adiabatic system $\quad 39$

3.3.4 The second law of thermodynamics 40

3.4 Free Energy and the Condition for Equilibrium at Constant

Temperature and Pressure $\quad 40$

3.4.1 The dependence of free energy on temperature and pressure 41

3.5 Partial Molar Quantities-Chemical Potential 41

3.6 Conditions for Equilibrium in Terms of Partial Molar Free Energy 42

3.6.1 Phase equilibrium $\quad 42$

3.6.2 Reaction equilibrium 43

3.7 Dependence of Chemical Potential on the Properties of the System 44

3.7.1 Dependence of chemical potential on pressure 44

3.7.2 Dependence of chemical potential on temperature 45

3.7.3 Dependence of chemical potential on composition 45

Further Reading 51

4 Phase Equilibria $\quad 52$

4.1 One-Component Systems 53

4.1.1 The thermodynamics of phase change in one-component systems 53

4.1.2 Graphical representation of one-component systems 53

4.2 Phase Diagrams and Two-Component Systems 55

4.3 Two-Component Liquid-Vapour Isothermal Phase Diagrams 55

$\begin{array}{ll}\text { 4.3.1 Nonideal behaviour } & 57\end{array}$

4.4 Calculation of Vapour Pressure 61

4.4.1 Antoine equation 62

4.4.2 Calingaert-Davis equation $\quad 62$

4.4.3 Craft's rule $\quad 62$

4.4.4 Ramsay and Young rule $\quad 62$

4.4.5 Duhring's rule 63

4.4.6 Cox-Othmer diagrams 64

4.5 Isobaric Two-Component Phase Diagrams 67

4.5.1 Two-phase liquid diagrams 67

4.5.2 Liquid-vapour isobaric phase diagrams 68

$\begin{array}{ll}4.6 \text { Distribution } & 70\end{array}$

4.6.1 Nernst distribution law 71

4.6.2 Thermodynamic basis of the Nernst distribution law 71

$\begin{array}{ll}\text { 4.6.3 The effect of association } & 72\end{array}$

$\begin{array}{ll}\text { 4.6.4 Nernst law and ionisation } & 72\end{array}$

$\begin{array}{lll}\text { 4.6.5 Extraction } & 73\end{array}$ 
4.7 Gas-Liquid Phase Systems 74

4.7.1 The effect of temperature $\quad 75$

4.8 Gas-Solid Phase Systems 75

4.8.1 Effect of temperature on gas-solid systems 77

4.9 Solid-Liquid Phase Systems 77

$\begin{array}{lll}\text { 4.9.1 Condensed systems } & 77\end{array}$

$\begin{array}{lll}4.9 .2 & \text { Isobaric solid-liquid phase diagrams } & 78\end{array}$

$\begin{array}{lll}4.9 .3 & \text { Thermal analysis } & 82\end{array}$

4.9.4 Differential thermal analysis $\quad 85$

4.10 Three-Component Phase Diagrams 88

4.11 Isothermal Three-Component Phase Systems 90

4.11.1 Determination of three-component diagrams 93

4.11.2 Intercomponent compound formation 96

4.12 Projected Nonisothermal Phase Diagrams 96

4.13 Liquid-Phase Regions in Three-Component Systems 98

Further Reading $\quad 99$

5 Distillation 100

5.1. Determination of Liquid-Vapour Equilibrium Compositions 100

$\begin{array}{ll}\text { 5.1.1 The use of Duhring diagrams } & 102\end{array}$

5.2 Continuous Distillation 104

5.2.1 Basic unit for continuous distillation 104

5.3 Calculation of the Degree of Separation in a Distillation 106

$\begin{array}{lll}\text { 5.3.1 Enriching section } & 106\end{array}$

$\begin{array}{lll}\text { 5.3.2 Stripping section } & 107\end{array}$

$\begin{array}{ll}\text { 5.3.3 Plate-to-plate calculations } & 107\end{array}$

5.4 Distillation of a Binary Mixture 108

5.5 The Graphical Method of McCabe and Thiele 109

$\begin{array}{ll}\text { 5.5.1 Equilibrium line } & 109\end{array}$

$\begin{array}{ll}\text { 5.5.2 Operating lines } & 109\end{array}$

5.5.3 Estimation of theoretical plates 110

5.6 Operating Line Limits in McCabe and Thiele Diagrams 111

5.6.1 Maximum reflux ratio 111

$\begin{array}{ll}\text { 5.6.2 Theoretical plates in packed columns } & 112\end{array}$

5.6.3 Minimum reflux ratio 112

5.7 The Effect of Feed Conditions in McCabe and Thiele Diagrams 113

5.8 The Equilibrium Line in McCabe and Thiele Diagrams 117

$\begin{array}{lll}\text { 5.8.1 The effect of pressure } & 117\end{array}$

5.8.2 Azeotrope formation 118

5.8.3 Heterogeneous azeotropes 119

5.9 Various Aspects of Distillation Problems 120

$\begin{array}{lll}5.9 .1 & \text { Design } & 120\end{array}$

5.9.2 Quantity specification 121

$\begin{array}{ll}5.9 .3 & \text { Quality specification } \\ & 123\end{array}$

5.10 Steam Distillation $\quad 124$

5.11 Azeotropic and Extractive Distillation 126

$\begin{array}{ll}5.12 \text { Molecular Distillation } & 127\end{array}$ 


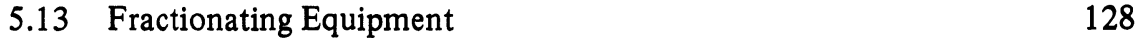

$\begin{array}{ll}\text { 5.13.1 Bubble-cap columns } & 128\end{array}$

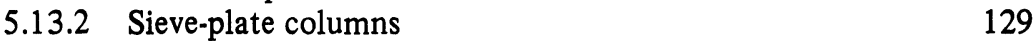

$\begin{array}{ll}\text { 5.13.3 Laboratory columns } & 129\end{array}$

$\begin{array}{ll}\text { 5.13.4 Packed columns } & 130\end{array}$

$\begin{array}{ll}\text { 5.13.5 Molecular still } & 130\end{array}$

5.14 The Efficient Use of Fractionating Equipment 131

$\begin{array}{lll}\text { 5.14.1 Mechanical carryover } & 131\end{array}$

$\begin{array}{lll}5.14 .2 & \text { Plate dumping } & 131\end{array}$

5.14.3 Hydrostatic effects on plates $\quad 132$

5.14.4 Packed-column efficiency 132

Further Reading 133

6 Extraction Processes 134

$\begin{array}{lll}\text { 6.1 Solid-Liquid Extraction: Leaching } & 134\end{array}$

$\begin{array}{ll}\text { 6.1.1 Minimum solvent flow in leaching } & 138\end{array}$

6.2 Leaching Equipment and its Use 141

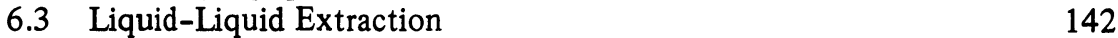

6.3.1 Single-batch extractions $\quad 142$

$\begin{array}{lll}\text { 6.3.2 Crosscurrent extraction } & 144\end{array}$

6.3.3 Countercurrent batch extraction-Hunter and Nash 146

$\begin{array}{ll}\text { 6.3.4 Continuous countercurrent extraction } & 148\end{array}$

6.4 Liquid-Liquid Extraction Equipment and its Use 149

$\begin{array}{ll}\text { 6.4.1 Drop formation and associated problems } & 149\end{array}$

$\begin{array}{lll}6.4 .2 & \text { Coalescence } & 150\end{array}$

$\begin{array}{ll}\text { 6.4.3 Charged-drop effects } & 150\end{array}$

6.5 Gas Treatment by Extraction 152

6.5.1 Gas extraction and theoretical extraction stages 152

$\begin{array}{ll}\text { 6.5.2 Degassing } & 153\end{array}$

$\begin{array}{lr}\text { Further Reading } & 154\end{array}$

7 Crystallisation 155

$\begin{array}{lll}7.1 & \text { Crystallisation in Two-component Systems } & 155\end{array}$

7.1.1 Crystallisation in two-component systems by cooling 155

7.1.2 Crystallisation in two-component systems by evaporation of solvent 156

$\begin{array}{ll}\text { 7.2 Crystallisation in Three-component Systems } & 158\end{array}$

7.2.1 Crystallisation in three-component systems by evaporation of solvent 158

7.2.2 Crystallisation in three-component systems by cooling 160

$\begin{array}{lll}7.3 & \text { Metastable Phase Diagrams } & 162\end{array}$

7.3.1 The origin of the metastable zone 163

$\begin{array}{lll}\text { 7.3.2 Nucleation and supersaturation } & 164\end{array}$

7.3.3 Mechanism of crystal growth 166

$\begin{array}{lll}7.4 & \text { Kinetics of Crystallisation } & 167\end{array}$

$\begin{array}{lll}7.5 & \text { Crystallisers } & 168\end{array}$

$\begin{array}{lll}\text { 7.5.1 Types of crystalliser } & 168\end{array}$

$\begin{array}{ll}\text { 7.5.2 Efficient operation of crystallisers } & 169\end{array}$

Further Reading 
8 Spectroscopic Methods of Analysis 173

8.1 Molecular Energy 173

8.2 Quantisation of Energy 174

8.3 The Origin of Spectra 174

8.4 Intensity-Concentration Relationships 176

8.4.1 Absorption spectra and the Beer-Lambert law 176

$\begin{array}{ll}\text { 8.4.2 Emission spectra } & 179\end{array}$

$\begin{array}{lll}8.5 & \text { Spectroscopic Units } & 179\end{array}$

8.6 Types of Spectra 180

8.7 Atomic Spectra 180

8.7.1 The electronic energy of an atom 180

8.7.2 Atomic-emission spectroscopy 182

8.7.3 Atomic-absorption spectroscopy 190

8.8 Molecular-Absorption Spectroscopy 190

8.9 Microwave Spectroscopy 190

8.9.1 The rotational energy of a diatomic molecule 191

8.9.2 The rotational absorption spectrum of a diatomic molecule 191

8.9.3 Application of microwave spectroscopy to chemical analysis 192

8.10 Infrared Spectroscopy 193

8.10.1 The vibrational energy of a diatomic molecule 193

8.10.2 The vibrational absorption spectrum of a diatomic molecule 194

$\begin{array}{ll}8.10 .3 & \text { The vibrations of polyatomic molecules } \\ 8.105\end{array}$

8.10.4 The vibrational absorption spectrum of a polyatomic molecule 198

8.10.5 Applications of infrared spectroscopy to chemical analysis 200

8.11 Raman Spectroscopy 201

8.12 Ultraviolet and Visible Spectroscopy 204

8.12.1 Electronic-absorption spectra of diatomic molecules 204

8.12.2 Electronic-absorption spectra of polyatomic molecules 206

8.12.3 Fluorescence and phosphorescence 208

8.12.4 Applications of electronic-absorption spectroscopy to chemical analysis 209

8.13 Nuclear Magnetic-Resonance Spectroscopy 213

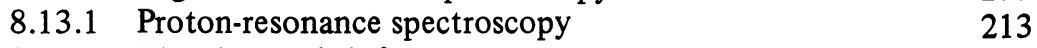

$\begin{array}{ll}\text { 8.13.2 The chemical shift } & 214\end{array}$

8.13.3 Spin-spin splitting 215

8.13.4 Applications of nuclear magnetic-resonance spectroscopy to

Further Reading chemical analysis 215

9 Reaction Equilibria $\quad 217$

$\begin{array}{ll}9.1 \text { The Equilibrium Constant } & 217\end{array}$

$\begin{array}{ll}\text { 9.2 Equilibria in Reactions between Ideal Gases } & 218\end{array}$

9.3 Equilibria in Reactions between Real Gases 219

9.4 Reaction Equilibria in Solution 220

9.5 Equilibria in Heterogeneous Reactions 221

9.6 The Standard Free-Energy Change of a Reaction 223

9.7 Dependence of the Equilibrium Constant on Temperature 224 9.7.1 Integration of the van't Hoff equation 225 
9.8 Dependence of the Standard Free-Energy Change on Temperature 226

9.9 Determination of the Thermodynamic Properties of Reactions 226

9.9.1 Experimental determination of equilibrium constants 226

9.9.2 Determination of equilibrium constants from calorimetric measurements-the third law of thermodynamics

9.9.3 Determination of equilibrium constants from spectroscopic measurements-statistical thermodynamics

9.9.4 Determination of equilibrium constants by groupsummation methods

9.10 Application of Thermodynamics to the Study of Reaction

Feasibility and Yield

9.10.1 Factors affecting reaction yield 233

$\begin{array}{ll}9.10 .2 & \text { Illustrative reactions } \\ 9 & 237\end{array}$

$\begin{array}{ll}9.10 .3 & \text { Simultaneous reaction equilibria } \\ 242\end{array}$

Further Reading

10 Chemical Kinetics

10.1 Reaction Order and Rate Constant 247

10.2 Rate Equations 248

10.2.1 Rate equation for a first-order reaction 248

10.2.2 Rate equation for a second-order reaction 250

10.2.3 Rate equation for a third-order reaction 251

10.3 Simultaneous Reactions 252

10.3.1 Consecutive reactions 252

10.3.2 Opposing reactions 253

10.3.3 Simultaneous side reactions 254

10.4 Identification of Reaction Characteristics 255

10.5 Determination of Reaction Order and Rate Constant 256

10.5.1 Substitution method 256

10.5.2 The differential-equation method 257

10.5.3 Half-period method 258

10.5.4 Isolation method 259

10.6 Effect of Temperature on Reaction Rate 260

10.6.1 The Arrhenius theory 260

10.6.2 The collision theory 260

10.6.3 Transition-state theory 262

10.7 Chain Reactions 265

10.7.1 Chain-polymerisation reactions 266

10.7.2 Explosive reactions 268

10.8 Homogeneous Catalysis 269

10.9 Isothermal Reactors 269

10.9.1 Batch reactors 270

10.9.2 Tubular-flow reactors 270

10.9.3 Continuously stirred reactors 271

10.10 Nonisothermal Reactors $\quad 272$

10.10.1 Adiabatic reactors 273

10.10.2 Nonadiabatic reactors 276

Further Reading 


\section{Ionic Reactions and Electrochemical Methods of Analysis}

11.1 Concentration Dependence of the Activity Coefficients of Ions in Solution

11.2 Acid-Base Equilibria

279

11.2.1 The $\mathrm{pH}$ scale $\quad 280$

$\begin{array}{lll}11.2 .2 & \text { Hydrolysis } & 282\end{array}$

11.2.3 Neutralisation curves $\quad 282$

11.2.4 Acid-base indicators $\quad 285$

$\begin{array}{lll}11.2 .5 & \text { Polybasic acids } & 285\end{array}$

11.2.6 Complex ions $\quad 286$

$\begin{array}{lll}11.3 & \text { Solubility and Precipitation } & 286\end{array}$

11.3.1 The effect of temperature on solubility 287

11.3.2 The effect of concentration on solubility 287

11.3.3 The effect of solvent on solubility 290

11.3.4 Homogeneous precipitation 292

$\begin{array}{lll}11.4 & \text { Electrolytic Conductance } & 292\end{array}$

11.4.1 Measurement of conductance and conductivity 293

11.4.2 Dependence of molar conductivity on concentration $\quad 294$

11.4.3 Independent ion migration 296

$\begin{array}{ll}\text { 11.4.4 Conductometric analysis } & 296\end{array}$

11.5 Reversible Electrode Processes 300

11.5.1 The electromotive force of reversible cells 300

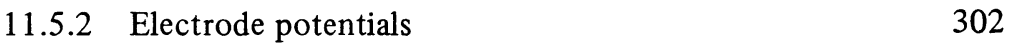

11.5.3 Reversible electrodes 303

11.5.4 Application of e.m.f. measurements to a determination of the thermodynamic properties of reactions 306

11.5.5 Potentiometric methods of analysis 308

$\begin{array}{lll}11.6 & \text { Irreversible Electrode Processes } & 312\end{array}$

$\begin{array}{lll}11.6 .1 & \text { Overpotential } & 312\end{array}$

$\begin{array}{lll}11.6 .2 \text { Electrolysis } & 318\end{array}$

$\begin{array}{lll}11.7 & \text { Polarography } & 321\end{array}$

11.7.1 Amperometry and amperometric titration 324

$\begin{array}{lll}11.8 & \text { Controlled-Potential Electrolysis } & 325\end{array}$

$\begin{array}{lll}\text { 11.8.1 Electrogravimetric analysis } & 325\end{array}$

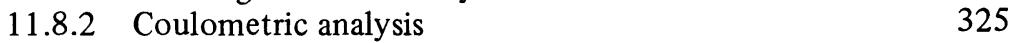

$\begin{array}{lll}11.9 & \text { Coulometric Titration } & 326\end{array}$

$\begin{array}{ll}11.10 \text { Electrorefining of Metals } & 328\end{array}$

$\begin{array}{ll}11.11 \text { Corrosion of Metals } & 329\end{array}$

$\begin{array}{ll}\text { 11.11.1 Protection against corrosion } & 331\end{array}$

Further Reading 333

12 The Chemistry of Surfaces and Subdivided Phases 334

$\begin{array}{lll}12.1 & \text { Adsorption at Liquid Surfaces } & 335\end{array}$

$\begin{array}{lll}12.1 .1 & \text { Surface films } & 338\end{array}$

$\begin{array}{ll}\text { 12.1.2 Applications of surface films } & 340\end{array}$

$\begin{array}{lll}12.2 & \text { Adsorption at Solid Surfaces } & 341\end{array}$

$\begin{array}{lll}\text { 12.2.1 Physical adsorption } & 341\end{array}$

12.2.2 Applications of physical adsorption 344 
Xii CONTENTS

$\begin{array}{lll}\text { 12.2.3 Chemisorption } & 346\end{array}$

12.2.4 Heterogeneous catalysis $\quad 347$

$\begin{array}{lll}12.3 & \text { Chromatography } & 349\end{array}$

12.3.1 Column chromatography 350

12.3.2 Paper chromatography 353

12.3.3 Thin-layer chromatography 353

$\begin{array}{lll}12.4 & \text { Disperse Systems } & 354\end{array}$

12.4.1 Colloids $\quad 354$

$\begin{array}{ll}12.4 .2 \text { Emulsions } & 362\end{array}$

$\begin{array}{lll}12.4 .3 & \text { Foams } & 363\end{array}$

$\begin{array}{lll}12.5 & \text { Filtration } & 364\end{array}$

12.5.1 Types of filter unit 364

$\begin{array}{lll}12.5 .2 & \text { Filtration rate equations } & 366\end{array}$

12.5.3 Constant-pressure filtration 367

12.5.4 Optimum time cycle in batch filtrations 369

$\begin{array}{ll}\text { 12.5.5 Continuous filtration } & 371\end{array}$

12.6 Surfactants and their Technical Applications 372

12.6.1 The nature of surfactant solutions 373

12.6.2 Surfactants as flocculating and dispersing agents 374

$\begin{array}{ll}12.6 .3 \text { Wetting } & 374\end{array}$

$\begin{array}{ll}\text { 12.6.4 Detergency } & 376\end{array}$

12.6.5 Classification of surfactants $\quad 378$

$\begin{array}{ll}\text { Further Reading } & 378\end{array}$

$\begin{array}{ll}\text { References } & 379\end{array}$

$\begin{array}{ll}\text { Index } & 381\end{array}$ 


\section{PREFACE}

This is a textbook of physical chemistry theory and the application of that theory to everyday industrial situations. Thus, although much of the content is of an essentially conventional character, it is presented in a manner that is more relevant to the requirements of a chemist employed in the manufacturing industries. Detailed treatment is included of such topics as phase-separation processes and instrumental methods of analysis, which receive only superficial treatment in most physical chemistry texts, while some of the more academic topics, such as the theory of molecular structure, have been omitted. Thus the student of chemistry will become acquainted with the fundamentals of physical chemistry while also recognising its relevance in a practical situation, and the student of chemical engineering will be familiarised with the essential relationships between physical chemistry and unit processes in the chemical and allied industries. Accordingly, the text has been liberally illustrated with worked (mainly industrial) numerical examples. Lack of space has prohibited the inclusion of further problems, but many similar examples will be found in Applied Physical Chemistry Problems, McGraw-Hill, London, 1968 by A. C. K. Smith

The SI system of units has been adhered to as far as possible, but in order to achieve realism it has been found necessary to make use of such quantities as parts per million (p.p.m.), weight/weight per cent (w/w\%) and the hour, which although not recommended in SI are nevertheless essential components of the language of the industrial chemist.

This book is designed to meet the needs of students of chemistry, applied chemistry and chemical engineering in universities, polytechnics and technical colleges, who are studying for qualifications ranging from H.N.C., H.N.D. and L.R.I.C. to C.N.A.A. and also B.Sc. degrees. In addition, chemistry graduates who are about to enter or are already in industry, will find this text an extremely useful reference book for many of the situations they may encounter.

The authors would like to thank their colleagues for the many lively and illuminating discussions that have helped in the preparation of this book.

Teesside Polytechnic,

C. HEALD

Middlesbrough,

A. C. K. SMITH 1974 


\section{GLOSSARY OF SYMBOLS}

As far as possible, internationally recommended symbols have been used throughout ${ }^{1}$. Given below is a list of the more important symbols used in this book, together with the name of the quantity to which each symbol refers. The number in parentheses denotes the chapter in which a symbol represents a given quantity; where no number is quoted, the symbol applies generally throughout the book. In a few cases the use of a symbol to represent two or more quite distinct quantities cannot be avoided, and where this occurs the exact meaning of a symbol is made clear in the associated text.

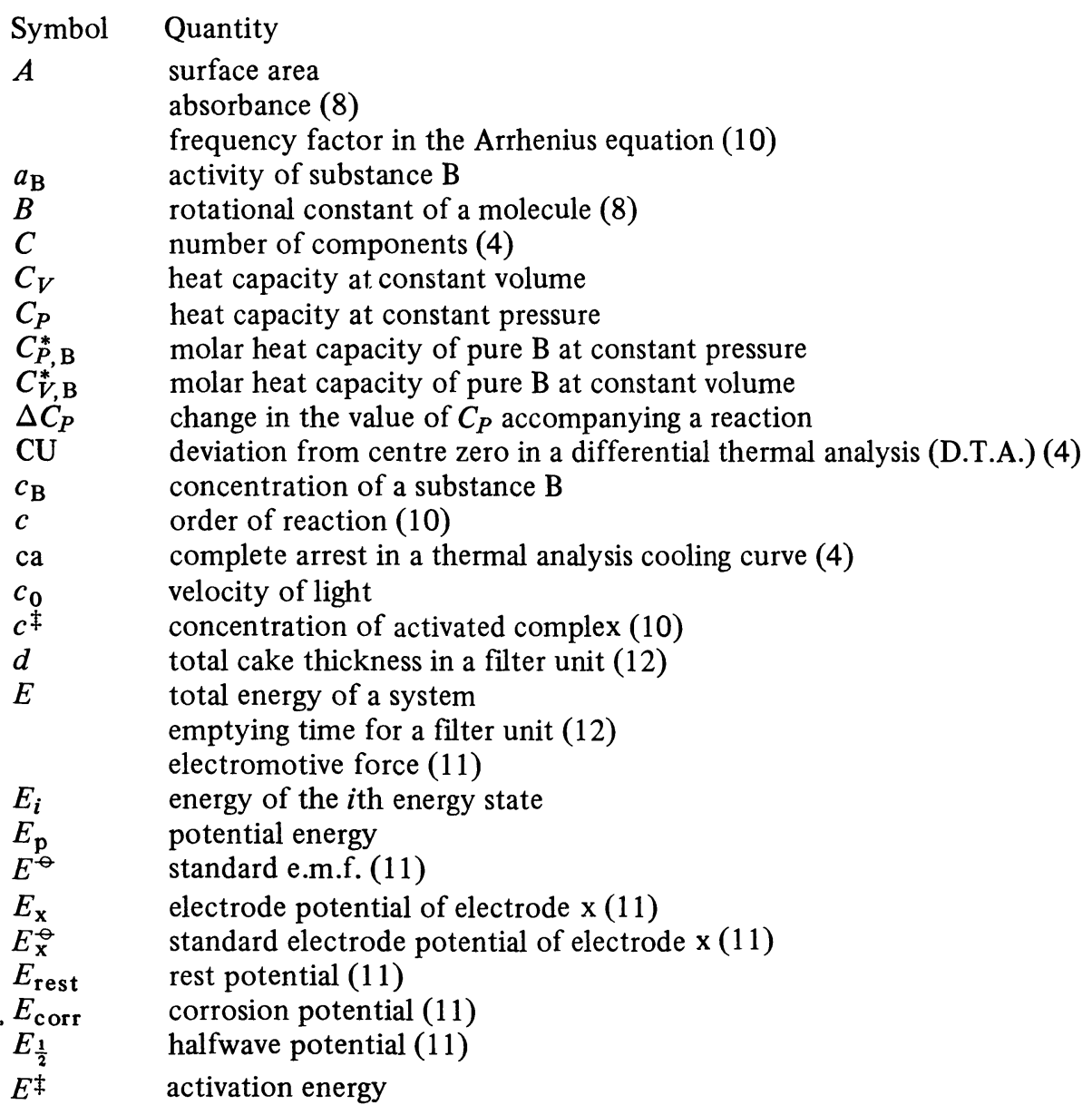


F $\quad$ Faraday constant (11)

moles of feed to a distillation column (5)

number of degrees of freedom

$F^{\prime} \quad$ number of degrees of freedom in a limited phase system (4)

$f \quad$ frequency of rotation of a drum filter (12)

$f_{\mathrm{B}} \quad$ fugacity or activity coefficient of substance $\mathrm{B}$

$f_{\mathrm{B}}^{*} \quad$ fugacity of pure substance $\mathrm{B}$

$G \quad$ free energy

conductance (11)

$G_{\mathrm{B}}^{*} \quad$ molar free energy of pure substance B

$G^{\text {s }} \quad$ surface free energy

$\Delta G \quad$ change in free energy

$\Delta G^{\ominus} \quad$ standard change in free energy

$\Delta_{\mathrm{f}} G^{\ominus} \quad$ standard free energy of formation

$\Delta G^{\mathrm{S}} \quad$ change in free energy associated with the formation of a crystal nucleus

(7)

$\Delta G_{\mathrm{v}} \quad$ free-energy change associated with the appearance of a new phase (7)

$\Delta G \ddagger \quad$ free energy of activation

$g$

$g_{i}$

$H$

acceleration due to gravity

statistical weight of the $i$ th energy state

enthalpy

magnetic field strength (8)

$H_{\mathrm{B}}^{*} \quad$ molar enthalpy of pure substance B

$H_{\mathrm{B}} \quad$ partial molar enthalpy of substance B

$\Delta H \quad$ change in enthalpy

$\Delta H_{\mathrm{v}} \quad$ molar enthalpy of vaporisation

$\Delta H^{\ominus} \quad$ standard enthalpy change

$\Delta_{\mathrm{f}} H^{\ominus} \quad$ standard enthalpy of formation

$h$

I

Planck constant

transmitted or emitted radiant intensity (8)

moment of inertia of a molecule (8)

nuclear spin quantum number (8)

ionic strength of a solution (11)

current (11)

$I_{0} \quad$ incident radiant intensity (8)

$I_{1} \quad$ limiting current (11)

$J \quad$ rotational quantum number (8)

rate of formation of free radicals (10)

$j \quad$ crystal shape factor (7)

current density (11)

$j_{0} \quad$ exchange current density (11)

$j_{1} \quad$ limiting current density (11)

$j_{\text {corr }} \quad$ corrosion current density (11)

$K \quad$ equilibrium constant

distribution coefficient (4)

permeability coefficient (12)

$K_{c} \quad$ concentration equilibrium constant

$K_{p} \quad$ pressure equilibrium constant

$K_{x} \quad$ mole fraction equilibrium constant

$K_{f} \quad$ fugacity equilibrium constant 


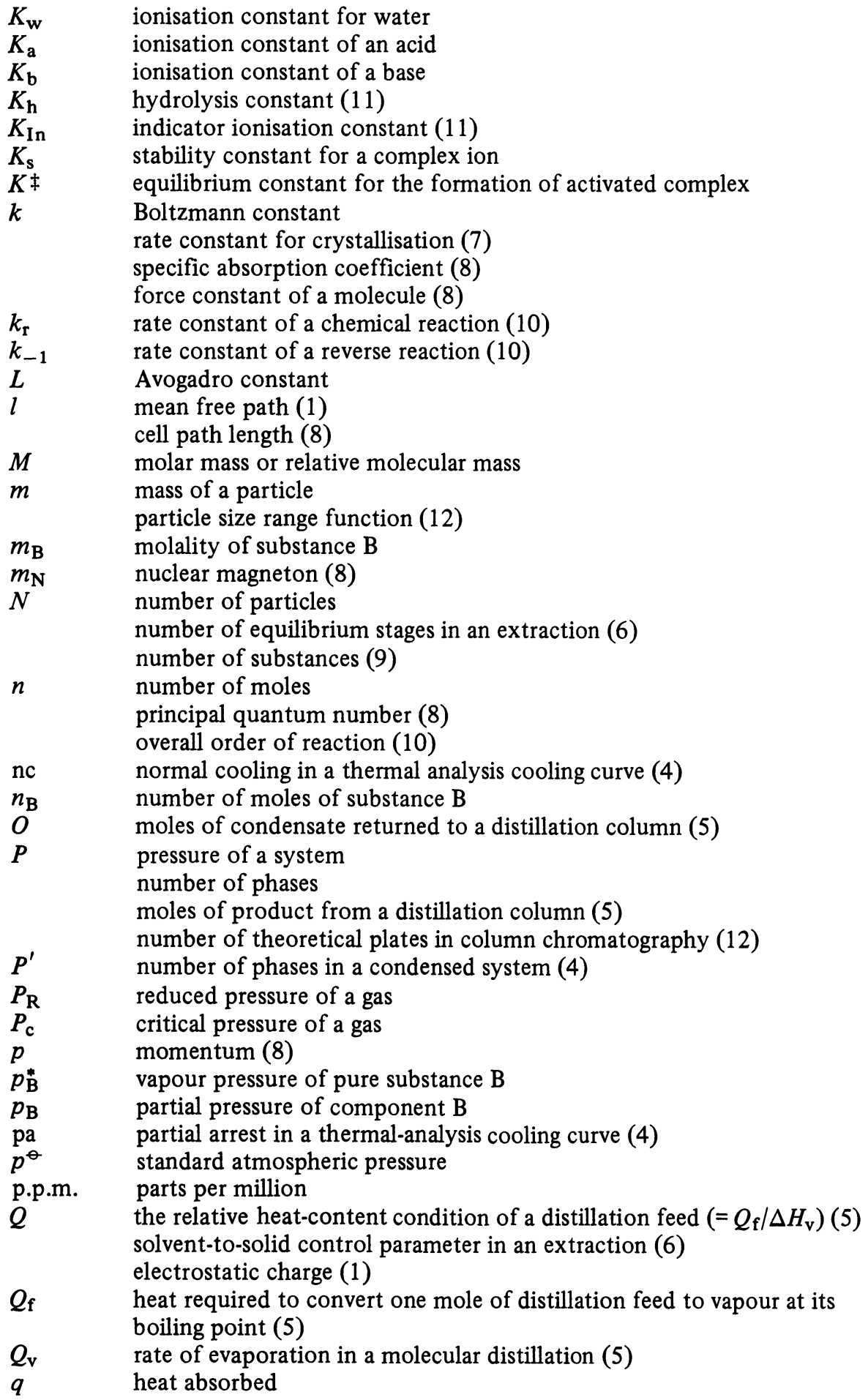


volume of solid per unit volume of filtrate (12)

$q_{V} \quad$ heat absorbed at constant volume

$q_{P} \quad$ heat absorbed at constant pressure

$q_{\text {rev }} \quad$ heat absorbed in a reversible process

$q_{\text {irrev }} \quad$ heat absorbed in an irreversible process

$q_{\mathrm{B}} \quad$ partition function of substance B (9)

$q_{\mathrm{t}} \quad$ translational partition function (9)

$q_{\mathrm{v}} \quad$ vibrational partition function (9)

$q_{\mathrm{r}} \quad$ rotational partition function (9)

$R \quad$ gas constant

reflux ratio (5)

distribution constant in a leaching process (6)

number of independent reactions (9)

electrical resistance (11)

filter medium resistance (12)

$R_{\mathrm{f}} \quad$ ratio of the distance moved by a species to that moved by the mobile phase in chromatographic separation (12)

$R_{\mathrm{M}} \quad$ a polarity parameter in chromatography (12)

$R_{\mathrm{X}} \quad$ ratio of the distance moved by a species to that moved by a reference species in chromatographic separation (12)

$r \quad$ particle radius (12)

$r_{\mathrm{cr}} \quad$ critical nucleus size (7)

$S \quad$ entropy

mass of pure solvent in an extraction (6)

output rate from a filter unit (12)

$S_{\mathrm{B}}^{*} \quad$ molar entropy of pure substance B

$S_{\mathrm{B}} \quad$ partial molar entropy of substance B

$\Delta S \quad$ change in entropy

$\Delta S^{\ominus} \quad$ standard entropy change

ST

$s$

$s_{\mathrm{B}}$

$T$

$T_{\mathrm{R}}$

$T_{\mathrm{c}}$

$T_{\mathrm{b}}$

$t$

start of a straight line portion in a D.T.A. curve (4)

filter cake compressibility function (12)

solubility of substance B

temperature

reduced temperature of a gas

critical temperature of a gas

normal boiling point of a liquid (4)

time

$t \frac{1}{2}$

half-period of a reaction (10)

thermodynamic energy

$U_{\mathrm{B}}^{*} \quad$ molar thermodynamic energy of pure substance $\mathrm{B}$

$U_{\mathrm{B}} \quad$ partial molar thermodynamic energy of substance $\mathrm{B}$

$u$

$\langle u\rangle$

$\left\langle u^{2}\right\rangle$

$V$

effective flow rate through a reactor (10)

mean velocity of a particle

mean square velocity of a particle

volume

moles of vapour leaving a distillation column (5)

$V_{\mathrm{r}} \quad$ effective volume of a reactor (10)

$V_{\mathrm{c}} \quad$ critical volume of a gas

$V_{\mathrm{R}} \quad$ reduced volume of a gas

$V_{\mathrm{B}}^{*} \quad$ molar volume of pure substance B 
$V_{\mathrm{B}} \quad$ partial molar volume of substance B vibrational quantum number (8) volume of solvent I (4) probability (3) moles of waste from a distillation boiler (5) mass of pure dry inert solid in an extraction (6) work done on a system composition parameter of substance B distance (12) mass of adsorbate adsorbed by unit mass of adsorbent (12) mole fraction of substance $B$ in liquid phase liquid coordinate of the point of intersection of the operating line in a McCabe and Thiele diagram (5) mass of adsorbate required to form a complete monolayer on the surface of unit mass of adsorbent (12) mole fraction of substance $B$ in the vapour phase activity coefficient of substance B vapour coordinate of the point of intersection of the operating line in a McCabe and Thiele diagram (5) mean activity coefficient of an electrolyte collision number compressibility of a gas (1) number of faradays passed during an electrochemical reaction (11) charge number of the $i$ th ion (11) exponential function in the Margules equation (4.7) efficiency factor in a molecular distillation (5) absolute degree of supersaturation (7) degree of ionisation (11) transfer coefficient (11) specific cake resistance (12) relative supersaturation (7) surface excess of substance B (12) surface or interfacial tension coefficient of supersaturation (7) kinetic chain length of a polymer (10) activity coefficient of substance $B$ fugacity coefficient of substance B chemical shift with respect to that of the tetramethyl silane protons, which is given the value 0

filter-cake thickness (12) molar absorption coefficient electrokinetic potential (12) viscosity overpotential (11) angle (12) fraction of adsorbent surface covered by adsorbate (12) conductivity (11) molar conductivity (11) molar conductivity at zero concentration (11) molar ion conductivity of the $i$ th ion (11) 
$\lambda \quad$ wavelength

$\mu \quad$ dipole moment (1)

reduced mass of a molecule (8)

chemical potential of a substance $B$

$\mu_{\mathrm{B}}$ standard chemical potential of substance $B$

chemical potential of a finely divided solid B (7)

stoichiometric coefficient for substance B taking part in a chemical reaction

frequency

$\bar{\nu} \quad$ wavenumber

$\xi \quad$ extent of reaction

$\pi \quad$ surface pressure (12)

$\rho$ density

$\sigma \quad$ collision diameter

$\sigma_{\mathrm{B}} \quad$ area occupied by one molecule of substance B in a surface (12)

$\tau$

chemical shift with respect to that of the tetramethyl silane proton, which is given the value of 10

$\psi \quad$ wave function (8)

electrostatic potential (11)

$\omega \quad$ frequency of a molecular vibration (8)

$\bar{\omega} \quad$ wavenumber of a molecular vibration (8) 